\title{
Role of matrix metalloproteinase 2 in the ovulatory folliculo-luteal transition of ewes
}

\author{
M. L. Gottsch, E. A. Van Kirk and W. J. Murdoch* \\ Department of Animal Science, University of Wyoming, Laramie, WY 82071, USA
}

Tissue dissolution and remodelling are associated with the processes of rupture of the ovulatory follicle and formation of the corpus luteum. Matrix metalloproteinase 2 (MMP-2) belongs to a family of endopeptidases that cleave extracellular proteins; its primary substrate is the lattice network of basement membranes that support epithelial cells and endothelium. The aim of this study was to ascertain a putative regulatory role of MMP-2 relevant to the folliculo-luteal transformation in ewes. Luteal regression and the preovulatory surge of gonadotrophins were synchronized by administration of $\mathrm{PGF}_{2 \alpha}$ and $\mathrm{GnRH}$ on days $\mathbf{1 4 . 0}$ and $\mathbf{1 5 . 5}$ of the oestrous cycle, respectively. Dominant antral follicles present during pro-oestrus consistently ovulate approximately $24 \mathrm{~h}$ after $\mathrm{GnRH}$ administration. Normal IgG or a bioactivity-neutralizing MMP-2 monoclonal antibody was injected into the antral cavity of preovulatory follicles at $8 \mathrm{~h}$ after $\mathrm{GnRH}$ administration. Jugular blood samples were obtained for serum progesterone analysis and ovaries were removed for light microscopic morphometry on day 8. A definitive ovulation stigma was evident in control ewes. The antra of ruptured follicles had largely been supplanted with luteal tissue. In contrast, the ovarian surface contiguous with follicles injected with anti-MMP-2 was smooth and undisturbed, which is indicative of a failure of ovulation. Luteinized unruptured follicles were filled with (entrapped) fluid. Corpora lutea of control animals contained numerous connective tissue projections that provided a framework for cellular migration and angiogenesis. Luteal tissues that surrounded the cavity of antibody-treated follicles lacked trabeculae and were deficient in blood vessels. Systemic venous progesterone concentrations were lower in ewes with a luteinized unruptured follicle compared with those with a corpus luteum. It is proposed that MMP-2 is a mediator of ovulation and luteal development.

\section{Introduction}

Matrix metalloproteinases (MMPs) function in the turnover of extracellular components during tissue remodelling. As a group (of at least 20), the MMPs degrade collagens, elastin, proteoglycans and adhesion molecules (Woessner, 1991; Birkedal-Hansen, 1995; Borkakoti, 1998). One member of the MMP family, MMP-2 (type IV collagenase/gelatinase A), because of its lytic effect on the type IV collagen-laminin backbone of basement membranes (Kühn, 1995; Aumailley and Smyth, 1998), could be of particular significance to the transformation of a follicle into a corpus luteum. Basal laminae that underpin granulosa cells and thecal endothelium are disrupted and reorganized during ovulation and luteinization (Bortolussi et al., 1989; Matsushima et al., 1996; Silvester and Luck, 1999; Fata et al., 2000).

There is a progressive increase in follicular MMP-2 production during the periovulatory period in ewes. MMP-2 was localized within connective tissue strands that extend into the substance of the corpus luteum and form an infrastructure for thecal invasion and neovascularization

*Correspondence

Email:wmurdoch@uwyo.edu
(Gottsch et al., 2000). The aims of the present study were to characterize the metamorphic and endocrine consequences of periovulatory follicular MMP-2 immunoneutralization.

\section{Materials and Methods}

This project was conducted with the approval of the University of Wyoming Animal Care and Use Committee. Reagents were purchased from Sigma Chemical Co. (St Louis, MO) unless indicated otherwise.

Mature western-range ewes were observed twice a day for oestrous behaviour in the presence of vasectomized rams. Day 0 was considered as day 1 of oestrus (cycles = 16-17 days). Luteal regression was synchronized by injection of $\mathrm{PGF}_{2 \alpha}$ (5 mg dinoprost tromethamine i.m.; Pharmacia and Upjohn, Kalamazoo, MI) on day 14 of the oestrous cycle. A preovulatory surge of gonadotrophins was elicited by administration of an agonistic analogue of $\mathrm{GnRH}(5 \mu \mathrm{g}$ des Gly ${ }^{10}-\mathrm{Ala}^{6}$ ethylamide i.m.) at $36 \mathrm{~h}$ after $\mathrm{PGF}_{2 \alpha}$ administration $(t=0 \mathrm{~h}$ ). Dominant antral follicles (approximately $6 \mathrm{~mm}$ in diameter) present during pro-oestrus will consistently ovulate at approximately $24 \mathrm{~h}$ after $\mathrm{GnRH}$ administration and generate normal corpora lutea (Roberts et al., 1985). 
Mid-ventral abdominal laparotomies were performed under general anaesthesia (sodium thiopental, i.v.; Abbott Laboratories, North Chicago, IL) using aseptic techniques. The reproductive tracts of ten ewes were exteriorized and a monoclonal MMP-2 antibody (MAB13405; Chemicon International Inc., Temecula, CA) or normal mouse IgG was injected $(4 \mu \mathrm{g}$ in $20 \mu \mathrm{l}$ PBS) into the antral cavity of preovulatory follicles at $8 \mathrm{~h}$ after $\mathrm{GnRH}$ administration $(n=5)$; in a preliminary study, the antibody dose neutralized MMP-2 bioactivity (eightfold increase versus $0 \mathrm{~h}$ ) in an extract of periovulatory (20 and $40 \mathrm{~h}$ ) follicles (for assay protocol, see Gottsch et al., 2000). Intrafollicular injections were made with a $100 \mu \mathrm{l}$ Hamilton glass syringe fitted with a 27-gauge hypodermic needle. The needle was inserted into the stroma of the ovary adjacent to the follicle and the tip was then directed into the antrum to avoid loss of antral fluid through the site of puncture.

Jugular blood samples for serum progesterone radioimmunoassay (Eggleston et al., 1990) were obtained by venepuncture and ovaries were removed on day 8 after GnRH administration. Tissue collections were made after the animals were killed (Beuthanasia-D i.v.; ScheringPlough Animal Health, Kenilworth, NJ). An ovarian papilla was considered to reflect the occurrence of rupture of the ovulatory follicle. Ovaries were cut in half and luteal structures were isolated by enucleation. A small segment of luteal tissue (approximately $10 \mathrm{mg}$ ) was excized and analysed for progesterone concentrations (McPherson et al., 1993).

The remaining portions of luteal tissue were fixed in Histochoice (Amresco, Solon, OH), washed in PBS, dehydrated, cleared, infiltrated with paraffin wax, cut into cross-sections at $5 \mu \mathrm{m}$ thickness, transferred on to microscope slides treated with subbing solution $(0.025 \%$ $(\mathrm{w} / \mathrm{v})$ chromium potassium sulphate, $0.25 \%(\mathrm{w} / \mathrm{v})$ gelatin), deparaffinized in xylene, rehydrated, stained in haematoxylin and eosin, and examined by light microscopy (Olympus $\mathrm{BH}-2$, Tokyo). Images of luteal sections were captured at $\times 400$ magnification by computer-interfaced high resolution digital photography (Pixera, Los Gatos, CA) and analysed (Optimas Software, Bothell, WA) for areas (percentage of total area represented) occupied by vascular (demarcated by endothelium) luminae. Numbers of granulosa-derived (large lutein) and theca-derived (small lutein, fibroblasts, endothelium) cells (Rodgers et al., 1984), with a nucleus in the section, were counted at $\times 1000$ magnification. Morphometric determinations were made within the outer, middle and inner zones of tissues. Four regions within two different sections per sample were evaluated for each parameter.

Assignments to treatments and selections of fields for microscopic inspection were made at random. Subsample data were averaged. Means were compared by Student's $t$ test or one-way ANOVA and protected least significant difference. Differences were considered significant at $P<0.05$.
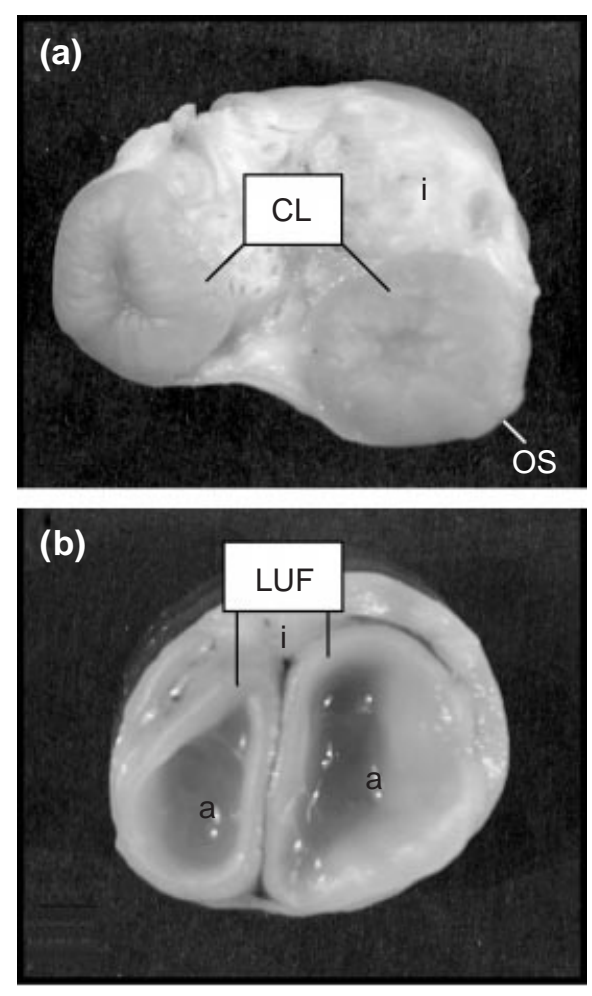

Fig. 1. In situ (bisected ovaries) gross morphology of ovine (a) corpora lutea $(\mathrm{CL})$ and (b) matrix metalloproteinase 2 (MMP-2) antibody-treated luteinized unruptured follicles (LUF) on day 8 after GnRH administration. i: interstitium; os: ovulation stigma; a: antrum.

\section{Results}

Follicles of control animals that were injected during the preovulatory period with non-immune mouse serum formed prototypical corpora lutea. Antral cavities of control follicles were replaced by luteinized tissue and ovulation papilla were evident (Fig. 1a). Intrafollicular injection of MMP-2 antibodies had apparently negated ovulation (that is, there was no morphological evidence of ovarian rupture). The walls of unruptured follicles were luteinized and distended (Fig. 1b) by antral fluid. The number of luteal structures represented within each treatment group was identical $(1.8 \pm 0.2)$.

The internal structures of corpora lutea contained a labyrinth of connective tissue extensions that was associated with blood vessels (Fig. 2a). There was a relative absence of an extracellular collagenous matrix and vasculature within luteal tissues of antibody-treated follicles (Fig. 2b).

Estimates of vascular space were used as a quantitative index of luteal angiogenic responses. The area of tissue cross-section comprised by vascular lumina was greater $(P<0.01)$ in corpora lutea than in luteinized unruptured follicles. There were no significant within-treatment differences in the degree of vascularization across the three zones of microscopic analysis (Fig. 3).

Cells of inferred thecal origin were interdispersed among large cells at similar proportions throughout the luteal 

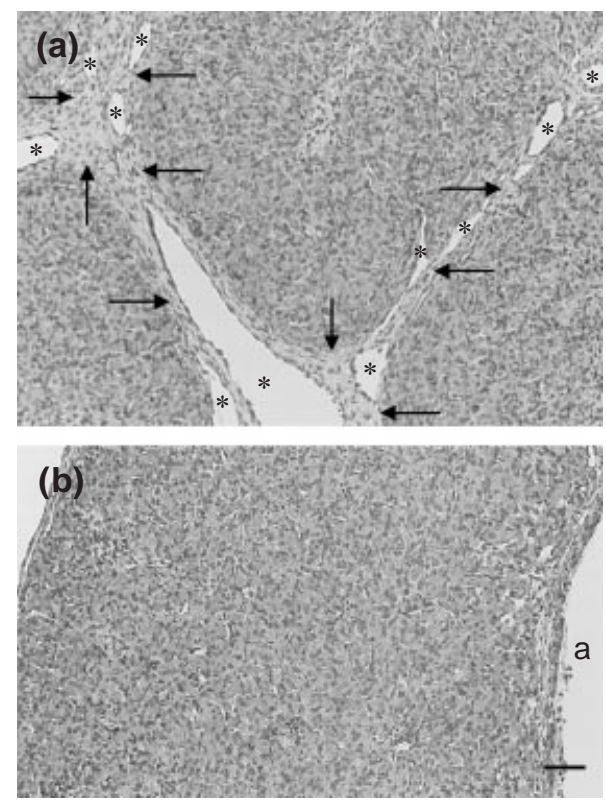

Fig. 2. Microscopic anatomy of (a) an ovine corpus luteum and (b) a wall of a luteinized unruptured follicle. Note the presence of connective tissue trabeculae (arrows) and abundance of blood vessels (asterisks) in (a). a: antrum. Scale bar represents $100 \mu \mathrm{m}$.

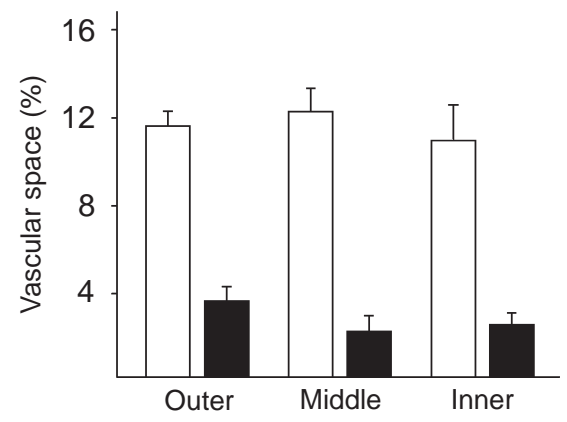

Fig. 3. Quantification of vascular luminal areas across different zones of cross-sections of ovine corpora lutea and luteinized unruptured follicles. $\square$ : Control (corpora lutea); $\mathbf{\square}$ : treated with matrix metalloproteinase 2 (MMP-2) antibody (luteinized unruptured follicles). Values are mean $\pm \mathrm{SE}$.

matrix of ovulatory controls (Figs 4 and $5 \mathrm{a}$ ). The distribution of types of cell within the wall of luteinized unruptured follicles was heterogeneous. Theca-derived cells were concentrated within the periphery of luteinized follicles, where comparatively few large luteal cells were observed $(P<0.05$ versus corpus luteum) (Figs 4 and $5 b)$. Thecal vestiges were essentially segregated from large luteal cells by a persistent basal lamina at points along the perimeters of luteinized unruptured follicles. Few cells of thecal lineage were found within the granulosa lutein tissues that predominated the central and adluminal zones $(P<0.01$ versus corpus luteum); these regions contained primarily large luteal cells $(P<0.05$ versus corpus luteum) (Figs 4 and

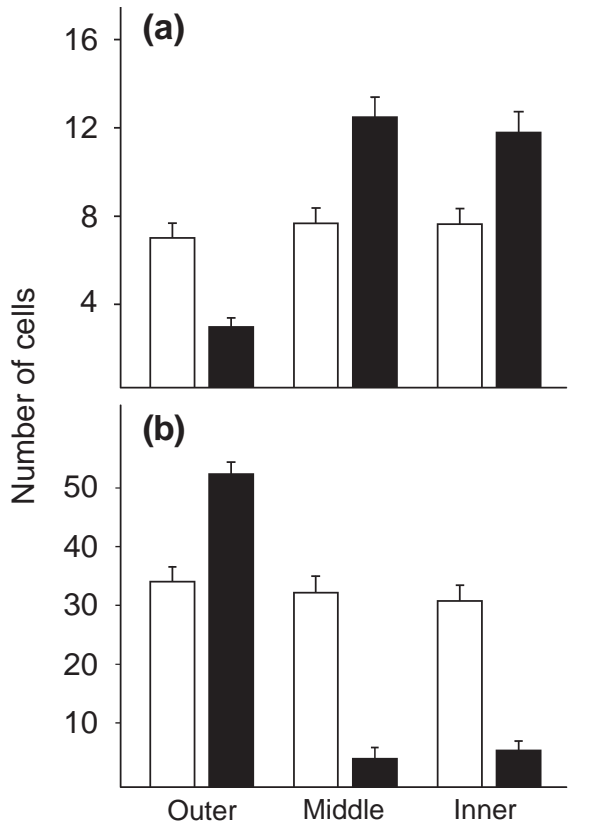

Fig. 4. Number of (a) granulosa-derived and (b) theca-derived cells within cross-sectional regions of ovine corpora lutea and luteinized unruptured follicles. $\square$ : Control (corpora lutea); treated with matrix metalloproteinase 2 (MMP-2) antibody (luteinized unruptured follicles). Values are mean \pm SE.
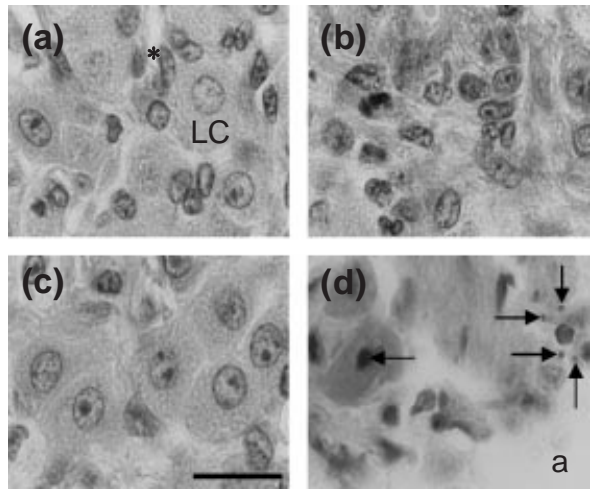

Fig. 5. Representative photomicrographs of ovine (a) corpora lutea (middle zone) and (b-d) luteinized unruptured follicles (b: outer; c: middle; d: inner). Asterisk: blood vessel; LC: large luteal cell. Arrows in (d) denote a large luteal cell with a pycnotic nucleus (left) and what appear to be residual bodies of a fragmented cell (right). a: antrum. Scale bar represents $30 \mu \mathrm{m}$.

5c). The cells that bordered the antral cavity of luteinized unruptured follicles appeared to be in various stages of ischaemic degeneration; large luteal cells with pycnotic nuclei and amorphous cytoplasm, residual bodies of fragmented (apoptotic) cells and extracellular spaces (not defined by endothelium) were especially evident (Fig. 5d).

Peripheral venous progesterone concentrations were approximately twice as high $(P<0.05)$ in animals with a corpus luteum compared with those with a luteinized 

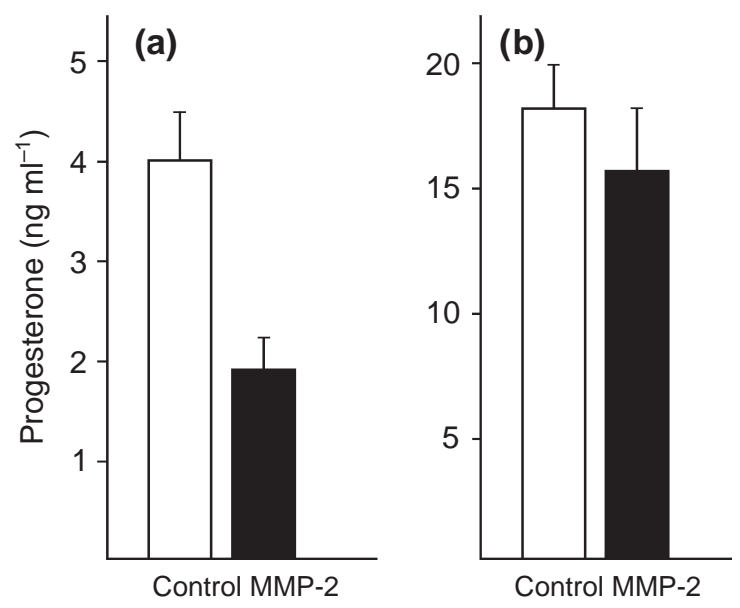

Fig. 6. Effects of intrafollicular injection of matrix metalloproteinase 2 (MMP-2) antibody on (a) peripheral (jugular) serum and (b) luteal progesterone concentrations in ewes. $\square$ : Control ewes; $\mathbf{\square}$ : ewes treated with matrix metalloproteinase 2 (MMP-2) antibody. Values are mean \pm SE.

unruptured follicle. Mean luteal concentrations of progesterone were higher in the control than in the MMP-2 antibody-treated group; however, this difference was not significant (Fig. 6).

\section{Discussion}

In addition to our experimental findings in sheep (Gottsch et al., 2000), increases in MMP-2 transcripts and type IV collagenolysis have been reported in periovulatory follicles of women (Puistola et al., 1986), rats (Reich et al., 1991; Curry et al., 1992, 2001; Bagavandoss, 1998; Liu et al., 1998, 1999) and monkeys (Chaffin and Stouffer, 1999). General chemical inhibitors of collagenases suppressed ovulation in hamsters (Ichikawa et al., 1983) and rats (Reich et al., 1985; Brännström et al., 1988). Novel results of this intrafollicular immunoblockade research indicate that MMP-2 plays a critical role in the biomechanics of ovulation and formation of the corpus luteum in ewes. We propose that MMP-2 degrades the fabric of basement membranes, which is necessary for ovulatory ovarian rupture to occur, and contributes to the reorganization of the thecal connective tissue foundation into a web-like mesh, which forms inroads into the granulosa compartment for endothelial and thecal cell infiltration, and provides a supportive structure for capillary sprouting. The underdeveloped vascular system of luteinized unruptured follicles would account for attenuated rates of progesterone delivery to the systemic circulation.

It is likely that there are diverse target actions of MMP-2 in periovulatory follicles. MMP-2 is not specific for structural elements of basement membranes and is capable of cleaving additional substrates, including collagens I, $\mathrm{V}, \mathrm{VII}, \mathrm{X}, \mathrm{XI}$ and $\mathrm{XIV}$, denatured collagen (gelatins), fibronectin, aggrecan, elastin and vitronectin (Woessner, 1991; Birkedal-Hansen, 1995; Borkakoti, 1998). Furthermore, MMPs can augment cellular proliferative responses by liberating growth factors from inhibitory binding proteins (Smith et al., 1999). There is a 10- to 20 -fold increase in size of the ovine corpus luteum during its differentiation phase; many of the mitotic cells are of endothelial origin (JablonkaShariff et al., 1993).

The biological effects of MMPs are dependent on de novo production, proteolytic activation and endogenous tissue inhibitor of matrix metalloproteinase (TIMP) concentrations. Transcriptional control of MMP-2 production in preovulatory ovine follicles is exerted by tumour necrosis factor $\alpha$ (TNF- $\alpha$ ) (Gottsch et al., 2000). Fibroblasts, endothelium and steroidogenic cells are targets for procollagenase upregulation (Reich et al., 1991; Haas and Madri, 1999; Curry et al., 2001). Excisions of latent (secreted) collagenases, permitting a second (autolytic) cleavage of the Cys- $\mathrm{Zn}^{2+}$ bond that stabilizes the propeptide, expose the catalytic domain of the enzymes. Plasmin, which is also generated in preovulatory follicles (Murdoch, 2000), cell-surface membrane-type (MT) MMPs and TIMP-2 (which forms a trimolecular complex with MT1-MMP and proMMP-2) are prospective facilitators of MMP-2 activation (Morgunova et al., 1999; Nagase and Woessner, 1999; Curry and Osteen, 2001) in luteinizing follicles (Liu et al., 1999; Smith et al., 1999). Tissue inhibitors of MMPs, which interact non-covalently on a $1: 1$ stoichiometric basis with enzymatic substrate-binding sites, limit the degree of extracellular damage that would otherwise be inflicted by untoward proteolysis (Nagase and Woessner, 1999), thereby ensuring that the extent of ovulatory tissue destruction does not circumvent the emergence of a viable corpus luteum (Smith et al., 1999).

Ovulatory dysfunction and luteal insufficiency are primary causes of infertility (Katz, 1988; Wathes, 1992). The aetiology of luteinized unruptured follicle syndrome is unknown; a disturbance in follicular MMP-2 production is a plausible determinant. An analogous condition is caused by intrafollicular injection of TNF- $\alpha$ antibodies (Gottsch et al., 2000). Immunization of ewes against inhibin also interfered with periovulatory follicular MMP-2 production and disrupted luteal development (Russell et al., 1995).

Proteolytic enzymes other than the plasminogen activator/ plasmin and MMP-2 systems have also been considered as potential regulators of alterations of periovulatory ovarian connective tissue. MMP-1 (interstitial collagenase) is an integral candidate intermediary of mammalian ovulation (Tsafriri, 1995; Smith et al., 1999; Murdoch, 2000; Curry et al., 2001). MMP-9 (gelatinase B) concentration was increased in the fluid of preovulatory follicles of pigs (Driancourt et al., 1998) and horses (Riley et al., 2001) and in formative corpora lutea or luteinized granulosa cells of rats (Nothnick et al., 1996), cattle (Goldberg et al., 1996; Zhao and Luck, 1996) and women (Duncan et al., 1998). Collagenase-3 (MMP-13), which degrades collagens I-III, was increased in preovulatory rat follicles (Balbin et al., 
1996; Komar et al., 2001). Cathepsin L, a lysosomal cysteine protease member of the papain family, and ADAMTS-1, a disintegrin and metalloproteinase with thrombospondin-like motifs, were induced in preovulatory follicles of rodents (Robker et al., 2000).

It is evident that ovarian morphogenesis during ovulatory cycles requires an interplay of proteases. An obligate function for MMP-2 may be species-dependent. Indeed, mice deficient in MMP-2 were fertile (Itoh et al., 1998). The absence of ovarian stigmata and the presence of unexpelled antral fluid indicate that inhibition of MMP-2 bioactivity might have prevented ovulation in the present study. Oocyte retention in luteinized unruptured follicles was not confirmed (notwithstanding, apoptotic atrophy and cytofragmentation after meiotic resumption/metaphase arrest would have been expected before day 8; Perez et al., 1999). The basement membrane that separates theca cells from granulosa cells appeared to be breached to some extent after intrafollicular injection of MMP-2 antibodies. These results indicate that either MMP-2 was not completely neutralized throughout the luteinization process or perhaps that redundancies in target actions of other enzymatic effectors were involved. Compensatory mechanisms would afford a degree of protection against a consummate failure of the ovulatory folliculo-luteal metamorphosis.

This work was supported by USDA-NRI Grant 01-02267.

\section{References}

Aumailley M and Smyth N (1998) The role of laminins in basement membrane function Journal of Anatomy 193 1-21

Bagavandoss P (1998) Differential distribution of gelatinases and tissue inhibitor of metalloproteinase-1 in the rat ovary Journal of Endocrinology 158 221-228

Balbin M, Fueyo A, Lopez JM, Diez-Itza I, Velasco G and Lopez-Otin C (1996) Expression of collagenase-3 in the rat ovary during the ovulatory process Journal of Endocrinology 149 405-415

Birkedal-Hansen H (1995) Proteolytic remodeling of extracellular matrix Current Opinion in Cell Biology 7 728-735

Borkakoti N (1998) Matrix metalloproteinases: variations on a theme Progress in Biophysics and Molecular Biology 70 73-94

Bortolussi M, Zanchetta R, Doliana R, Castellani I, Bressan GM and Lauria A (1989) Changes in the organization of the extracellular matrix in ovarian follicles during the preovulatory phase and atresia Basic and Applied Histochemistry 33 31-38

Brännström M, Woessner JF, Jr, Koos RD, Sear CH and LeMaire WJ (1988) Inhibitors of mammalian tissue collagenase and metalloproteinases suppress ovulation in the perfused rat ovary Endocrinology 122 $1715-1721$

Chaffin CL and Stouffer RL (1999) Expression of matrix metalloproteinases and their tissue inhibitor messenger ribonucleic acids in macaque periovulatory granulosa cells: time course and steroid regulation Biology of Reproduction 61 14-21

Curry TE, Jr and Osteen KG (2001) Cyclic changes in the matrix metalloproteinase system in the ovary and uterus Biology of Reproduction 64 1285-1296

Curry TE, Jr, Mann JS, Huang MH and Keeble SC (1992) Gelatinase and proteoglycanase activity during the periovulatory period in the rat Biology of Reproduction 46 256-264

Curry TE, Jr, Song L and Wheeler SE (2001) Cellular localization of gelatinases and tissue inhibitors of metalloproteinases during follicular growth, ovulation, and early luteal formation in the rat Biology of Reproduction 65 855-865

Driancourt MA, Quesnel H, Meduri G, Prunier A and Hermier D (1998) Luteinization and proteolysis in ovarian follicles of Meishan and Large White gilts during the preovulatory period Journal of Reproduction and Fertility 114 287-297

Duncan WC, McNeilly AS and Illingworth PJ (1998) The effect of luteal rescue on the expression and localization of matrix metalloproteinases and their inhibitors in the human corpus luteum Journal of Clinical Endocrinology and Metabolism 83 2470-2478

Eggleston DL, Wilken C, Van Kirk EA, Slaughter RG, Ji TH and Murdoch WJ (1990) Progesterone induces expression of endometrial messenger RNA encoding for cyclooxygenase Prostaglandins 39 675-683

Fata JE, Ho ATV, Leco KJ, Moorehead RA and Khokha R (2000) Cellular turnover and extracellular matrix remodeling in female reproductive tissues: functions of metalloproteinases and their inhibitors Cellular and Molecular Life Sciences 57 77-95

Goldberg MJ, Moses MA and Tsang PC (1996) Identification of matrix metalloproteinases and metalloproteinase inhibitors in bovine corpora lutea and their variation during the estrous cycle Journal of Animal Science 74 849-857

Gottsch ML, Van Kirk EA and Murdoch WJ (2000) Tumour necrosis factor $\alpha$ up-regulates matrix metalloproteinase-2 activity in periovulatory ovine follicles: metamorphic and endocrine implications Reproduction, Fertility and Development 12 75-80

Haas TL and Madri JA (1999) Extracellular matrix-driven matrix metalloproteinase production in endothelial cells: implications for angiogenesis Trends in Cardiovascular Medicine 9 70-77

Ichikawa S, Ohta M, Morioka H and Murao S (1983) Blockage of ovulation in the explanted hamster ovary by a collagenase inhibitor Journal of Reproduction and Fertility 68 17-19

Itoh T, Tanioka M, Yoshida H, Yoshioka T, Nishimoto $\mathbf{H}$ and Itohara S (1998) Reduced angiogenesis and tumor progression in gelatinase Adeficient mice Cancer Research 58 1048-1051

Jablonka-Shariff A, Grazul-Bilska AT, Redmer DA and Reynolds LP (1993) Growth and cellular proliferation of ovine corpora lutea throughout the estrous cycle Endocrinology 133 1871-1879

Katz E (1988) The luteinized unruptured follicle and other ovulatory dysfunctions Fertility and Sterility 50 839-850

Komar CM, Matousek M, Mitsube K, Mikuni M, Brännström $M$ and Curry TE, Jr (2001) Effects of genistein on the periovulatory expression of messenger ribonucleic acid for matrix metalloproteinases and tissue inhibitors of metalloproteinases in the rat ovary Reproduction 121 259-265

Kühn K (1995) Basement membrane (type IV) collagen Matrix Biology 14 439-445

Liu K, Wahlberg P and Ny T (1998) Coordinated and cell-specific regulation of membrane type matrix metalloproteinase 1 (MT1-MMP) and its substrate matrix metalloproteinase 2 (MMP-2) by physiological signals during follicular development and ovulation Endocrinology 139 4735-4738

Liu K, Olofsson JI, Wahlberg P and Ny T (1999) Distinct expression of gelatinase A [matrix metalloproteinase (MMP-2)], collagenase-3 (MMP-13), membrane type MMP 1 (MMP-14), and tissue inhibitor of MMPs type 1 mediated by physiological signals during formation and regression of the rat corpus luteum Endocrinology 140 5330-5338

McPherson LA, Van Kirk EA and Murdoch WJ (1993) Localization of stress protein-70 in ovine corpora lutea during prostaglandin-induced luteolysis Prostaglandins 46 433-440

Matsushima T, Fukuda Y, Tsukada K and Yamanaka N (1996) The extracellular matrices and vascularization of the developing corpus luteum in rats Journal of Submicroscopic Cytology and Pathology 28 441-445

Morgunova E, Tuuttila A, Bergmann U, Isupov M, Lindqvist Y, Schneider G and Tryggvason K (1999) Structure of human pro-matrix metalloproteinase-2: activation mechanism revealed Science $\mathbf{2 8 4}$ 1667-1670

Murdoch WJ (2000) Proteolytic and cellular death mechanisms in ovulatory ovarian rupture Biological Signals and Receptors 9 102-114

Nagase $\mathbf{H}$ and Woessner JF, Jr (1999) Matrix metalloproteinases Journal of Biological Chemistry 27421 491-21 494 
Nothnick WB, Keeble SC and Curry TE, Jr (1996) Collagenase, gelatinase, and proteoglycanase messenger ribonucleic acid expression and activity during luteal development, maintenance, and regression in the pseudopregnant rat ovary Biology of Reproduction 54 616-624

Perez GI, Tao XJ and Tilly JL (1999) Fragmentation and death (a.k.a. apoptosis) of ovulated oocytes Molecular Human Reproduction 5 414-420

Puistola U, Salo T, Martikainen H and Ronnberg L (1986) Type IV collagenolytic activity in human preovulatory follicular fluid Fertility and Sterility 45 578-580

Reich R, Tsafriri A and Mechanic GL (1985) The involvement of collagenolysis in ovulation in the rat Endocrinology 116 522-527

Reich R, Daphna-Ilken D, Chun SY, Popliker M, Slager R, Adelmann-Grill BC and Tsafriri A (1991) Preovulatory changes in ovarian expression of collagenases and tissue metalloproteinase inhibitor messenger ribonucleic acid: role of eicosanoids Endocrinology 129 1869-1875

Riley SC, Gibson AH, Leask R, Mauchline DJW, Pedersen HG and Watson ED (2001) Secretion of matrix metalloproteinases 2 and 9 and tissue inhibitor of metalloproteinases into follicular fluid during follicle development in equine ovaries Reproduction 121 553-560

Roberts AJ, Dunn TG and Murdoch WJ (1985) Induction of ovulation in proestrous ewes: identification of the ovulatory follicle and functional status of the corpus luteum Domestic Animal Endocrinology 2 207-210

Robker RL, Russell DL, Yoshioka S, Sharma SC, Lyndon JP, O'Malley BW, Espey LL and Richards JS (2000) Ovulation: a multi-gene, multi-step process Steroids 65 559-570

Rodgers RJ, O'Shea JD and Bruce NW (1984) Morphometric analysis of the cellular composition of the ovine corpus luteum Journal of Anatomy $\mathbf{1 3 8}$ 757-769
Russell DL, Salamonsen LA and Findlay JK (1995) Immunization against the $\mathrm{N}$-terminal peptide of the inhibin $\alpha 43$-subunit $(\alpha \mathrm{N})$ disrupts tissue remodeling and the increase in matrix metalloproteinase-2 during ovulation Endocrinology 136 3657-3664

Silvester LM and Luck MR (1999) Distribution of extracellular matrix components in the developing ruminant corpus luteum: a wound repair hypothesis Journal of Reproduction and Fertility 116 187-198

Smith MF, McIntush EW, Ricke WA, Kojima FN and Smith GW (1999) Regulation of ovarian matrix remodelling by metalloproteinases and their tissue inhibitors: effects on follicular development, ovulation and luteal function Journal of Reproduction and Fertility Supplement $\mathbf{5 4}$ $367-381$

Tsafriri A (1995) Ovulation as a tissue remodeling process - proteolysis and cumulus expansion Advances in Experimental Biology and Medicine 377 121-140

Wathes DC (1992) Embryonic mortality and the uterine environment Journal of Endocrinology 134 321-325

Woessner JF, Jr (1991) Matrix metalloproteinases and their inhibitors in connective tissue remodeling FASEB Journal 5 2145-2154

Zhao Y and Luck MR (1996) Bovine granulosa cells express extracellular matrix proteins and their regulators during luteinization in culture Reproduction, Fertility and Development 8 259-266

Received 8 April 2002.

First decision 17 May 2002.

Accepted 27 May 2002. 